\title{
Research on Urbanization Promotion and Qiang Culture Protection
}

\author{
Meiyu Qin
}

Management School, Chengdu University of Information Technology, Chengdu, 610225, China

\author{
Keywords: Qiang area, Urbanization, Protection, Inheritance
}

\begin{abstract}
The post-disaster reconstruction for cities and towns in Qiang area has been completed. The ecosystem of Qiang culture continuously suffers threat and challenge in the social practice of post-disaster reconstruction, industrial reconstruction, and new rural construction, thus how to confront the dramatic change in ecological environment and realize the coordinated development of urban construction and Qiang cultural protection becomes the key for ecological development of Qiang culture. On the basis of analysis on uniqueness and diversity of Qiang culture, this paper carries out analysis and summary on Qiang culture protection and inheritance paths in the practice process of post-disaster reconstruction and urbanization promotion for the purpose of providing certain theoretical and empirical reference for practice of urbanization promotion in minority areas under the background of post-disaster reconstruction.
\end{abstract}

\section{Long-standing and well-established Qiang culture}

Qiang culture is created by Qiang people based on their natural environment, it is the result of social civilization through many times of blending and many layers of development, it is the wisdom and crystallization of Qiang people, and it is an important part of Chinese culture. So far, the earliest character discovered in China is oracle bone script of Shang Dynasty more than 3,000 years ago; the character “㒸” is the only title about nationality (clan or tribe) in oracle bone script, and the character “㒸” is the earliest record of nationality title in China. "Qiang refers to sheepherders in northwest China”, and the Qiang nationality takes sheep as their totem. According to the history, Yan Emperor, that is, Shennongshi, is an branch of Qiang ancestors who change to agriculture at the earliest time, and most of Qiang people live a nomadic life; Qiang people have their own language but no character. Therefore, Qiang culture reflects the earliest memory of Chinese civilization. The specific reflection is shown as below:

View of harmony between human and natural environment. So far, Qiang people's religious faith is still at preliminary stage; they worship god of sky, god of mountains, god of ground, god of sheep, and god of tree, and take white for luckiness and kindness. In Qiang people's eyes, the milk white quartz stone is the embodiment of gods, and this belief is reflected at the folk custom content closely related to Qiang people's life such as dwellings, festivals, and costume as well as the harmonious and kind temperament while they communicate with people of other nationality. As Mr. Fei Xiaotong says, "Qiang nationality is a nationality which makes blood transfusion towards outside world". Many nationalities, including Han nationality, have the bloodline of ancient Qiang people. Today, in the process of building socialism with Chinese characteristics, this kind of nationality temperament is worth awing and praising.

Tangible and intangible cultural heritage. The Qiang culture mentioned in this paper refers to Qiang culture of overall significance, and it covers the content of three subsystems (nature, society, and economy), especially refers to tangible and intangible cultural heritage which have typical cultural features and are closely related to Qiang people's life. The tangible cultural heritage includes Qiang costume, food, cities and towns, villages, buildings, and other explicit tangible cultural heritage. Take Qiang blockhouse, a unique and exquisite building form of Qiang nationality, as an example: the builder builds the blockhouse only by virtue of imagination, the materials are rubbles, and the yellow mud is used as adhesive to build a 13/14-storey building without drawing, suspension wire, and column support. The intangible cultural heritage includes Qiang language, folk custom, folk art, folk handicraft, protocol and festivals and other implicit intangible cultural heritage. For example, Qiang flute, as one of core cultural symbols of Qiang nationality, was listed into national-level 
intangible cultural heritage in 2006, and it is famous for its rhythm, tone, and playing skills, etc. Those forms of heritage show rich details of Qiang culture and bright local color, and they become the important content of list of intangible cultural heritage at each level and key culture relic protection sites after disaster.

In terms of spatial level, Qiang culture is characterized by large volume, wide distribution, strong diversity, and it becomes the important content of social practice of nature, society, and economy system in the area in different periods; in terms of temporal level, Qiang culture is a kind of culture which blends with multi-source culture, that is, it takes ancient Qiang culture of Minjiang river valley as the subject and absorbs Han and Tibetan culture. Due to Qiang tribe, geographical environment, adaptive capacity, and other metabolism, Qiang culture realizes diversified development.

\section{Urbanization promotion and Qiang culture protection}

\section{Towns and Qiang cultural ecology}

The "cultural ecology" is applied in the theory and practice of anthropology at the earliest time, and it is the basic concept of "cultural ecology science". Julian Steward defines cultural ecology as the relation of mutual reaction between human culture and behavior and the natural ecological environment they live ${ }^{[1]}$, and later the cultural ecology is often used to analyze interaction mechanism of various factors in cultural ecology system. Qiang cultural ecology refers to the anti-disturbance self-adaptive system in which Qiang people make use of deconstruction, reconstruction, testing, updating, and other series of manual technique activities to effectively promote the formation of coupling of Qiang cultural, natural, and socioeconomic system in the cultural ecology system while they face the objective reality of change in ecological environment after disaster. In the practice of national culture development, the cultural ecology can be only used as guiding principle for benign development of national culture; however, the spatial formation mechanism of cultural area and specific development paths are the key to carry out practical guidance and provide reference for benign development of national cultural ecology.

It is pointed out in Overall Planning for Qiang Cultural Ecology Protection Experimental Area that the cultural space refers to the self-adaptive and recombination process of cultural ecology system in specific historic period; in terms of technology and operation, it has regional spatial unit with the significance of typical and complete cultural representative, and it is the spatial expression and result of deconstruction and reconstruction, verification and adjustment of Qiang culture in the social changing process. According to Lefebvre's spatial production theory, on the basis of previous relevant result, the development space of post-disaster urban reconstruction culture ecology is divided into urban public space, urban public cultural space, urban commercial space, urban tourism space, and urban architectural landscape space.

The urban public space includes urban function, layout, street, square, pavilion, and other landscape design content; it is the high-level spatial carrier of Qiang cultural ecological development, it determines the property and feature of towns, it requires the premise condition such as system, policy, and industry, and it is the ideal spatial environment for ecological development of Qiang culture. Therefore, the realization of post-disaster urban cultural space requires backbone position of tourism or great historic opportunity and other objective condition.

The urban public cultural space includes museum, folk museum, culture center, film center, teenage center and other kinds of public cultural space carrier which undertakes materials, system, and spiritual culture, and it is the natural selection and result of urban construction with Chinese characteristics in the process of urbanization promotion. In particular, under the guidance of new concept of urbanization, the urban public cultural space can meet people's appeal for "cultural factor" well.

The urban commercial space includes training school, various kinds of workshop, entrepreneurial activities which can solve the survival problem and other kinds of spatial carriers. Compared to above two kinds of cultural space, the urban commercial space focuses on the subject's use value, and the urban public space and urban public cultural space pay attention to the use value of objects such as government and expert. Through tourism activities, it is able to improve the cultural subject's 
awareness of protection and inheritance and realize the effective connection between subject's use value and object's exchange value.

The urban tourism space includes urban park, greenbelt, agricultural sightseeing belt and other tourism cultural space; it is the common cultural spatial carrier for creating modern urban tourism products and has typical use feature. There is no vacuum development environment for any culture, and the urban tourism space is the development path through which the non-mainstream culture depends on cultural tourism to realize mutual growth with urban space.

The urban architectural landscape space includes the overall scene of central city area and rural architecture; the scene of central city area is greatly influenced by property and function of city; once the central city area is formed, it is hard to make changes. The rural architecture is the best spatial carrier of national cultural protection and inheritance, and it forms a countryside space for active inheritance of national culture together with local people's production and life ways; it is the factor which determines the use value of national culture subject.

\section{Practice of urbanization promotion and Qiang culture protection}

The earthquake seriously damages the order of practice space, representation space, and ecological space of Qiang culture which takes industry, towns, and villages as carrier and is formed over many years; after disaster, the survival environment of Qiang culture suffers unprecedented challenge. The material practice space of Qiang culture is destroyed, which is reflected at the situation that the stockaded villages which engage in traditional high-mountain and semi-high- mountain agriculture and animal husbandry are destroyed, thus many herdsmen who live in high mountain move out of high mountain and seek for new settlement; the towns in valley and river valley as well as interior street and community suffer different degree of destroying, thus the order of urban space of Qiang culture shall be urgently reconstructed; the economic industrial base and pattern in Qiang area suffers serious damage, which influences and changes Qiang people's way of production and life as well as values. The development path for economic industry of Qiang culture remains to be innovated.

After disaster, the urbanization promotion provides a new chance of ecological development for Qiang culture protection. The earthquake proposes serious challenge for survival environment of Qiang culture, and the post-disaster reconstruction provides Qiang culture with more open and complicated ecological development environment and spanning-development chance. The urban reconstruction is the prime task of post-disaster reconstruction. The continuous improvement of urban architectural space of Qiang culture greatly improve the cultural connotation of towns and become the soul of towns. The rapid recovery and revitalization of tourism provide a chance for economic development mode of urban endogenous industry. Qiang culture not only becomes the core power which drives prosperous development of tourism, but also realizes effective protection and inheritance in tourism products, landscape space, and lines. The new rural construction is realized under institutional arrangement of post-disaster reconstruction fund, and the quality of rural roads, and public service is greatly improved, which improves local people's living standard to certain degree. It can be seen that Qiang culture realizes the reconstruction of cultural ecology on the basis of urban reconstruction, tourism reconstruction, and new rural construction so as to realize the purpose of effective protection and inheritance.

\section{Contribution of Qiang cultural protection and inheritance in the process of urbanization promotion - take “Qiang cultural ecological protection experimental area” as a case}

The fundamental purpose for establishment of Qiang cultural ecological protection experimental area is to make use of the practice chance of various social reconstruction to realize integrated development and create a natural ecological environment good for sustainable development of Qiang culture on the basis of admitting the objective fact that the earthquake cases serious damage on Qiang cultural tangible and intangible heritage. Through urban overall protection and productive protection of tourism, those achievements of civilization which gather historic, artistic, humanistic, and scientific value of Qiang nationality not only can realize inheritance and continuation in the form, but also can combine their cultural spirit with modern lifestyle to realize the modernized transition. 
Therefore, the establishment of experimental area is of great significance for rescuing and protecting Qiang cultural heritage, inheriting excellent Chinese culture, quickening the step of post-disaster reconstruction in Qiang area, and realize a spanning development.

The cultural ecological protection area refers to specific area which focuses on protecting the intangible cultural heritage, and carries out overall protection on cultural forms with rich historical and cultural accumulation, good existence state, special value and bright features, including intangible cultural heritage, so as to promote all-around and sustainable development of economic society. Through definition of cultural ecological protection, it can be known that the theoretical subject of protection is intangible cultural heritage; however, from perspective of operation, the practice subject of protection is various forms of spatial areas which undertake the intangible cultural heritage. The Qiang cultural ecological protection experimental area takes Mao County as the core area, Wenchuan County, Li County, and Beichuan Qiang Autonomous County of Mianyang City as key scope of protection. Qiang culture depends on the relevant chance of urban space and economic industry provided by the interactive development of post-disaster urbanization construction and tourism reconstruction in Qiang area to complete the transition among cultural form, type of business, and ecology and then improve the survival ability of Qiang culture in new period.

In the process of large-scale urban and rural space, industrial and livelihood reconstruction in Qiang area, various kinds of blending paths are adopted, which practically and effectively play a protection and inheritance function in Qiang culture. Firstly, through urban space creating, image updating, rural large-scale construction, and small-town spatial integration, a 'binary" condition is provided for ecological development of Qiang culture. Secondly, after disaster, many featured industrial clusters of cultural tourism in Qiang area have been preliminarily established, which realizes the effective interaction between cultural accumulation area and enrichment area of tourism resource. Numerous items of Qiang culture are protected and inherited in activity space of tourism industry such as tourist attraction, tourism town, streets, and theatre, and the object's exchange value is deeply excavated, such as Qiang embroidery, Qiang flute, and Shibi. Thirdly, the post-disaster ecological development of Qiang culture has strong project symbiosis, which is reflected at the interdependent development of periphery reconstruction projects such as small towns, industry, and new countryside, and the development of specific form of Qiang culture driven by typical heritage items. In a word, a benign interaction is basically realized between urbanization promotion and Qiang cultural protection and inheritance in Qiang area; they promote and depend on each other.

\section{Conclusion}

The fact that many featured towns and active tourism market emerge in Qiang area in recent years shows that the post-disaster Qiang culture changes from passive state to active state; it adopts integrated path to realize an interactive development with small town space, tourism, and planning projects, and form numerous significant achievements of cultural space and cultural project, which preliminarily realizes the benign development of cultural ecology. Meanwhile, the tourism small-town construction also forms new threat and challenge for ecological development of Qiang culture. For example, due to similar ecological development path of Qiang culture, the cultural space form and type of operation have strong convergence; besides, the level of subjective awareness of reconstruction subject influences reconstruction projects of Qiang culture. In the process of large-scale post-disaster urbanization promotion, there still exist many deficiencies in the practice of Qiang culture reconstruction, and those deficiencies will be continuously adjusted and perfected in new urbanization road so that Qiang culture can truly become the source power for sustainable development of social sustainable development in Qiang area.

\section{Acknowledgments}

This paper is the phased objective of the project of National Social Science Foundation of China (12XMZ072), the general project of Sichuan Provincial Education Department Qiang Science 
Research Center (QXY1406), and Sichuan Provincial Tourist Administration Young Tourism Expert -Funding Project (SCTYETP2015L22).

\section{References}

[1] Qin Meiyu, Wu Jianguo: Research on Ecological Development Mechanism of National Culture in Tourism Field and Countermeasures, People's Tribune, 2013 (01).

[2] Hu Huilin: Outline of Temporal and Spatial Cultural Economy, Exploration and Free Views, 2013 (5): 10-16.

[3] Guo Wen et al.: Research on Multi-dimensional Spatial Production of Cultural Heritage Sightseeing Area Based on Field Theory - Take Zhouzhuang Ancient Town in Yangtze River Delta as an Example, Human Geography, 2013(2):117-124.

[4] Zhang Xiaoping et al. Practice of Intangible Cultural Heritage Protection and Tourism Survival Based on Cultural Space Theory, Academic Exploration, 2010(12):105-109. 